\title{
The International Effects of U.S. Farm Subsidies
}

\author{
Eric O'N. Fisher and Harry de Gorter
}

\begin{abstract}
Using dynamic programming, this paper examines effects of farm subsidies on U.S. exports of corn, cotton, rice, and wheat. The six policy simulations described here explore alternative proposals in the current round of the General Agreement on Tariffs and Trade. The analysis leads to two conclusions. First, abolishing domestic subsidies lowers world prices of these crops. Second, imposing tighter supply controls may not actually decrease exports in the short run.
\end{abstract}

Key words: agricultural exports, dynamic programming, General Agreement on Tariffs and Trade.

Diplomatic initiatives in the Uruguay Round of the General Agreement on Tariffs and Trade (GATT) may require reform of both domestic and foreign farm subsidies. The international community has put forward several proposals, each offering a particular measure of industry protection. ${ }^{1}$ Countries insist on simple protection measures in order to negotiate multilateral reductions in domestic distortions, but such an ideal may be quixotic. We show below, for example, that policies attempting to tighten agricultural supply controls or reduce subsidies may not reduce output. Indeed, the effects of subsidy reforms depend upon farmers' expectations and the rent-seeking behavior of farms of different sizes and qualities.

Policymakers faced an easier task in the Kennedy Round, where manufacturing was protected predominantly by tariffs and other $a d v a$ lorem distortions. In the current round, the GATT "framework agreement" of 1989 envisages using an aggregate measure of support; signatories

Eric O'N. Fisher is an assistant professor, Department of Economics, Cornell University; Harry de Gorter is an assistant professor, Department of Agricultural Economics, Cornell University.

The authors would like to thank Stephen V. Marks, Kathryn Marshall, two anonymous referees, and seminar participants at the November 1990 Midwest International Economics Meetings, Cornell University, and the University of Chicago for comments on earlier drafts. The authors will make available at cost a computer diskette with the data, programs, and all results described in the text.

This research was supported in part by the U.S. Department of Agriculture under Cooperative Agreement 58-3AEJ-0-80038. The views expressed in this paper are solely those of the two authors. Review coordinated by Steve Buccola.

' A good summary is given by the International Agricultural Research Trade Consortium (1990b). are to agree to a common percentage reduction in this measure. ${ }^{2}$ The most frequently cited protection measure is the "Producer Subsidy Equivalent" (PSE), the per-unit transfer to farmers as a proportion of revenues. Because the PSE may not capture all distortionary effects of agricultural policy, the GATT (1989b) is also considering effects of supply controls.

We describe six hypothetical policy scenarios and use dynamic programming to show their effects on markets for the major American export crops: corn, cotton, rice, and wheat. Each policy represents elements of diplomatic initiatives considered in the GATT. The first policy replicates the status quo. The second policy eliminates subsidies entirely; we find this typically lowers price and increases supply. The third policy freezes base acreages at 1987 levels, raising price and decreasing supply. The fourth policy halves the PSE for each crop by reducing target price and diversion payments and has little effect on markets. The fifth policy doubles payments for land left fallow, causing outputs of some crops actually to rise slightly. The sixth policy doubles acreage set-aside requirements, creating only modest output reductions.

\section{Literature Review}

Two different strands in the literature analyze the policy influences on exports of field crops

\footnotetext{
2 See the GATT's Mid-Term Meeting, MTN.TNC/11, Geneva, 21 April 1989a. The International Agricultural Trade Research Consortium (1990a) reviews many alternative measures.
} 
from the United States. The first strand uses ad valorem measures to capture subsidies' general equilibrium effects (Hertel; Tyers and Anderson; Trela, Whalley, and Wigle). For a survey of this literature, see Robinson. The second strand is devoted to individual commodity studies (Schmitz, Sigurdson, and Doering; McCalla and Josling) and follows the standard approach of Wallace, depicting acreage diversion as a leftward shift in a crop's supply curve. Such an analysis is static and ignores many features of American farm policy. Gardner criticizes both strands of research for their lack of policy detail and for ignoring the Lucas critique.

Although we use traditional techniques to describe market demand, our model of market supply attempts to face Gardner's criticism. It incorporates many details of the political economy of American agricultural subsidies. Unlike earlier approaches, it includes the relation between subsidies and historical plantings, the requirement that farmers leave land fallow to receive a subsidy, and the special payments farmers receive for acreage not planted. Our model emphasizes that a farmer's participation is voluntary. Using static price expectations, each farmer solves a stationary dynamic program depending explicitly on government policy.

Our solution technique draws on Rust by using a nested fixed-point algorithm to solve the farmer's dynamic program for each static price path. The algorithm searches for a price approximating zero excess demand.

\section{The Model}

The present model extends the earlier one in de Gorter and Fisher by allowing for uncertainty, farm-specific costs, variable land qualities, and endogenous determination of world price.

We begin by defining a vector of policy parameters:

$$
\theta=(\tau, \gamma, \delta, \psi, L),
$$

where $\tau$ is the target price, $\gamma$ is the diversion payment in dollars per unit not planted, $\delta$ is the diversion requirement, $\psi$ is program yield, and $L$ is loan rate in dollars. Parameter $\delta \in[0,1)$ is the proportion of base acreage left fallow in order to qualify for subsidies. The target price is known at time of planting. The diversion payment is paid for units not produced, an aspect of these programs often noted in the popular press. The farmer is paid subsidies based upon program yield. ${ }^{3}$ This yield is specific to each farmer, independent of vagaries of weather and land fertility, and known at time of planting. The loan rate is a price floor maintained by the federal government.

Let the farmer have base acreage $x_{t}$ and plant acreage $u_{t}$. The farmer's costs per acre planted are

$$
\begin{aligned}
& c\left(x_{t}, u_{t}\right) \\
& = \begin{cases}F x_{t}+v u_{t} & \text { if } u_{t} \leq x_{t} \\
F u_{t}+v u_{t}+\alpha F\left(u_{t}-x_{t}\right)^{2} & \text { otherwise, }\end{cases}
\end{aligned}
$$

where $F$ is fixed cost, $v$ is variable cost, and $\alpha$ is a quadratic adjustment parameter. Three comments are in order: first, farms with large base acreage have large fixed costs; second, farmers pay constant variable cost per planted acre; third, farmers pay a quadratic adjustment cost if they expand plantings beyond base acreage. The quadratic term captures the increasing opportunity cost of plantings beyond a historical norm. Since we use data on the full economic costs of planting, parameter $\alpha$ is a penalty beyond the cost of acquiring and improving new land. The cost function depends explicitly upon base acreage in a natural way, with large farms having high fixed costs and low marginal costs.

Let the world price of the crop be $p$. The farmer receives two kinds of subsidies: deficiency payments and diversion payments. Deficiency payments are

$$
s_{1}\left(p, u_{t} ; \theta\right)=(\tau-\max \{p, L\}) \psi u_{t},
$$

where the first term is the markup of target price above the maximum of loan rate and market price, and the second term shows subsidies are based upon program yield. Diversion payments are

$$
s_{2}\left(x_{t}, u_{t} ; \theta\right)=\gamma \psi \max \left\{0,\left(x_{t}-u_{t}\right)\right\},
$$

where $\gamma$ is payment for a unit not planted. These subsidies are also based upon program yields and can never be negative. A farmer receives a maximum of $\$ 50,000$ per year; hence total subsidies are

$$
s\left(p, x_{t}, u_{t} ; \theta\right)=\min \left\{s_{1}(\cdot)+s_{2}(\cdot), 50000\right\} .
$$

Subsidies depend upon market price, government policy, base acreage, and planted acreage.

The farmer's decision is the solution to a sta-

\footnotetext{
${ }^{3}$ Program yields have been fixed since the middle part of the last decade, giving incentives for farmers with declining expected yields to participate.
} 
tionary dynamic program. State variable $x_{t}$ is base acreage, and control $u_{t}$ is planted acres. At $t$, the time of planting, actual yield and price of output may be uncertain. Let $\tilde{\mu}$ be a random variable describing actual yield and let $\tilde{p}$ be the analogous variable describing market price. Then a farmer in the subsidy program has expected revenues as follows:

$$
g\left(x_{t}, u_{t} ; \theta\right)=E\left[s\left(\tilde{p}, x_{t}, u_{t} ; \theta\right)+\tilde{p} \tilde{\mu} u_{t}\right]
$$

This expectation is based on the information available to the farmer at time of planting. American farmers receive both subsidies and revenues from sale of crops. Price expectations are static since they are independent of $t$.

Now define the following:

$$
h\left(x_{t}, u_{t} ; \theta\right) \equiv g\left(x_{t}, u_{t} ; \theta\right)-c\left(x_{t}, u_{t}\right),
$$

where $h\left(x_{t}, u_{t} ; \theta\right)$ denotes the net expected revenues a participating farmer receives from planting $u_{t}$ acres on base acreage $x_{t}$. The farmer's reward is

$$
\begin{aligned}
& r\left(x_{t}, u_{t} ; \theta\right) \\
& \quad= \begin{cases}h\left(x_{t}, u_{t} ; \theta\right) & \text { if } u_{t} \leq(1-\delta) x_{t} \\
E\left[\tilde{p} \tilde{\mu} u_{t}\right]-c\left(x_{t}, u_{t}\right) & \text { otherwise, }\end{cases}
\end{aligned}
$$

where the expectation is taken with respect to the farmer's information set at planting. Equation (4) describes the program's voluntary aspect: the farmer's discrete choice of whether to participate. If he participates, his expected profits are $h\left(x_{t}, u_{t} ; \theta\right)$; otherwise, he receives expected profits from selling his crop on the market.

Current planting choice influences next year's base acreage in a deterministic way. In the United States, base acreage is currently defined as a fiveyear moving average of past plantings. ${ }^{4}$ Hence,

$$
x_{t+1}=\left\{\begin{array}{l}
.8 x_{t}+.2 \delta x_{t}+.2 u_{t} \\
x_{t} \\
.8 x_{t}+.2 u_{t}
\end{array}\right.
$$

where $x_{t+1}$ is base acreage in period $t+1$. Set $x_{t+1}=z\left(x_{t}, u_{t}\right)$ for future reference. This function states that a farmer can expand base acreage by planting more than his current base. If a farmer fallows the required amount of acreage, his base acreage is left unchanged. Hence his "considered plantings" are his full base. Finally, a farmer

\footnotetext{
${ }^{4}$ See 7 U.S.C. 1464. Program yields used to be defined as a five-year moving average, but the low and high years were excluded.
}

can decrease base acreage by idling more land than required.

Let $X$ be the state space and $U$ be the control space. The solution to the farmer's dynamic program is characterized by

$$
V\left(x_{t} ; \theta\right)=\max _{u_{t} \in U} r\left(x_{t}, u_{t} ; \theta\right)+\beta E\left[V\left(x_{t+1} ; \theta\right)\right],
$$

where $\beta$ is the discount factor and $x_{t+1}$ is given by (5). A farmer with base acreage $x_{t}$ following an optimal planting scheme has $V\left(x_{t} ; \theta\right)$ as the present value of expected profits.

The solution to (6) is the farmer's optimal planting decision:

$$
u_{t}=\pi\left(x_{t} ; \theta\right) .
$$

A farmer's plantings depend upon base acreage, government policy, and expectations about all stochastic variables relevant to the planning problem. The analysis in de Gorter and Fisher describes several aspects of $\pi\left(x_{t} ; \theta\right)$ in a simpler model. In that case, farmers with small base opt out, since historical plantings are insufficient to take full advantage of subsidies. Farmers with large base participate because it is not worthwhile to increase base by sacrificing current subsidies. The behavior of farms with intermediate base is indeterminate. These aspects of the farmer's planting program are inherent in the comparative dynamics below.

To complete the description of market supply, we need to determine the aggregate effect of the farmers' decisions. Let the number of farmers be $N$ and the observed density of base acreages be $f\left(x_{t}\right) .{ }^{5}$ Then the aggregate output of the crop is

$$
\begin{aligned}
& \text { if } u_{t}<(1-\delta) x_{t} \\
& \text { if }(1-\delta) x_{t} \leq u_{t} \leq x_{t} \\
& \text { if } x_{t}<u_{t}
\end{aligned}
$$

(8) $S(\theta)=N \int_{x_{t} \in X}\left[E_{\bar{\mu}}\right] \pi\left(x_{t} ; \theta\right) f\left(x_{t}\right) d x_{t}$.

Market supply depends upon government pol-

\footnotetext{
${ }^{5}$ A referee pointed out astutely that we are limiting the analysis by taking $N$ and $f\left(x_{t}\right)$ as fixed. The ergodic distribution of base acreage is endogenous, and it depends upon long-run forecasts of government policy and a fully explicit formulation of the price path induced by a new policy.
} 
icy, the expectations of each farmer, average yield, and the distribution of farm base acreages.

The market's demand side consists of three elements: domestic demand, foreign demand, and accumulation of stocks. Domestic demand is given by the simple function $D^{h}(p)=\lambda p^{\varepsilon}$, where $\lambda$ and $\varepsilon$ are parameters to be determined from data on domestic consumption. Likewise, foreign demand is given by $D^{f}(p)=\lambda^{*} p^{\varepsilon^{*}}$, where $\lambda^{*}$ and $\varepsilon^{*}$ are determined from data on exports. We model the accumulation (or decumulation) of inventories as an exogenous flow; let us denote this by $\Delta I .{ }^{6}$ Then world demand for crops produced in the United States is

$$
D(p)=D^{h}(p)+D^{f}(p)+\Delta I,
$$

where all functions and variables are as above.

This enables us to define a partial equilibrium for government policy $\theta$ as a price $p$ such that

$$
Z(p ; \theta)=D(p)-S(\theta)=0 .
$$

Since there is no analytical solution, it is necessary to use numerical methods to simulate these equilibria.

\section{Data and Simulation Method}

Table 1 presents policy parameters for corn, cotton, rice, and wheat in 1987. Complete data on distributions of base acreage for these crops in 1987 were obtained from the U.S. Department of Agriculture's Agricultural Stabilization and Conservation Service. The data describe only the state and county of farms having base; they

\footnotetext{
${ }^{6}$ This is the accumulation of inventories by both private agents and the public sector. Although (9) is a description of market demand, the accumulation of inventories is used to maintain the loan rate in the Payment-in-Kind (PIK) program. Farmers' expectations about these stocks are captured in expecied reward function (4).
}

do not indicate farmers' participation decisions. Base acreages follow classical exponential distributions.

Although our model uses continuous state and control spaces, it is necessary to make these spaces discrete in practical applications. We divided the state space into forty intervals:

$$
\mathscr{b}=\{[0,4],[5,9], \ldots,[200, \infty)\} .
$$

Although the last category contains farms of widely different sizes, the percentages of farms in this class were only $3.5 \%$ for corn, $6.0 \%$ for cotton, $20.8 \%$ for rice, and $6.5 \%$ for wheat. Since these farms produce a disproportionate share of output, we pay special attention to them in describing the different policies below. Finally, the choice of forty dimensions was dictated by computational considerations.

The number of farms and total base acreage are available for each category. We defined the state space $X=\left\{x_{1}, \ldots, x_{40}\right\}$ as the within-group average acreage. Note that $X$ depends upon the distribution of farms for the crop in question. We set the control space $U=X$. Because these are discrete approximations, transition rule (5) is no longer entirely accurate. Define $x_{41} \equiv \infty$, and let $x_{t} \in X$ and $u_{t} \in U$, where both sets are now discrete. Then the transition is $\hat{z}: X \times U$ $\rightarrow X$ whose rule is

$$
\hat{z}\left(x_{t}, u_{t}\right)=x_{i} \leftrightarrow z\left(x_{t}, u_{t}\right) \in\left[x_{i}, x_{i+1}\right),
$$

where $x_{i}$ is the $i$ th element of $X$. It is difficult for a farmer to build up base because he must plant enough acreage to attain the average, not minimal, farm size in any category.

Since we did not have data on yields for each farm, we modeled the heterogeneity of farm qualities by assuming that yields follow independent symmetric binomial distributions across base acreage categories. Mean yields for corn, cotton, rice, and wheat were set at actual historical yields from national data in 1987, and

Table 1. Market Prices and Policy Parameters in 1987

\begin{tabular}{lcccccc}
\hline & $\begin{array}{c}\text { Market } \\
\text { Price } \\
(p)\end{array}$ & $\begin{array}{c}\text { Target } \\
\text { Price } \\
(\tau)\end{array}$ & $\begin{array}{c}\text { Loan } \\
\text { Rate } \\
(L)\end{array}$ & $\begin{array}{c}\text { Diversion } \\
\text { Factor } \\
(\delta)\end{array}$ & $\begin{array}{c}\text { Diversion } \\
\text { Payments } \\
(\gamma)\end{array}$ & $\begin{array}{c}\text { Program } \\
\text { Yield } \\
(\psi)\end{array}$ \\
\hline Corn & $\$ 1.94$ & $\$ 3.03$ & $\$ 1.82$ & 0.314 & $\$ 0.59$ & 104.0 \\
Cotton & $\$ 0.64$ & $\$ 0.79$ & $\$ 0.52$ & 0.286 & $\$ 0.00$ & 593.0 \\
Rice & $\$ 7.27$ & $\$ 11.66$ & $\$ 6.84$ & 0.392 & $\$ 0.00$ & 46.8 \\
Wheat & $\$ 2.57$ & $\$ 4.38$ & $\$ 2.28$ & 0.312 & $\$ 0.00$ & 35.0 \\
\hline
\end{tabular}

Source: U.S. Department of Agriculture, Historical Commodity Data Series: 1950-1987.

Notes: Prices are dollars per bushel, pound, or cwt., as relevant. Diversion payments are in dollars per bushel, pound, or cwt. not planted. Program yields are in bushels, pounds, or cwt. per acre, as relevant. 
standard deviations were calculated from yields for 1980 through 1987 . $^{7}$

The cost function (2) was calibrated using fixed and variable costs per acre in McElroy, Ali, Dismukes, and Clauson. The quadratic adjustment parameter $\alpha$ was the only variable used to fit actual data in 1987. We assumed $\alpha$ was the same for both yields and searched for a value predicting within $1 \%$ of historical output. Adjustment parameters were calibrated at $1.5 \times$ $10^{-2}, 1.0 \times 10^{-1}, 1.0 \times 10^{-1}$, and $5.9 \times 10^{-4}$ for corn, cotton, rice, and wheat respectively. The interpretation of these values is that farmers must pay the full economic cost of planting and a further penalty to plant more than base acreage. For example, planting ten acres beyond base costs a corn farmer $\$ 2467$; the analogous costs for cotton, rice, and wheat are $\$ 8591, \$ 8198$, and $\$ 1161$ respectively. The low value for wheat reflects the ease of bringing marginal land into

\footnotetext{
${ }^{7}$ The mean yields in 1987 for corn, cotton, rice, and wheat were $119.8,702,55.55$, and 39.8 respectively. Their respective standard deviations were $13.2,83.2,4.6$, and 2.1 . Table 1 gives the units
} and source for these data. cultivation, and the high value for rice indicates how difficult it is to assure plentiful supplies of water on new land. Although the quadratic penalty is paid only in the first year, farmers pay higher fixed costs in every subsequent year to maintain the expanded base. Still, some programs are so lucrative that farmers plant beyond base in anticipation of higher future subsidies.

Figure 1 presents results of the calibration for a low-yield corn farm; other crops and farm yields are similar. Units on the two horizontal axes are acres; those on the vertical axis are expected present-value dollars. To keep the scales manageable, the surface has been truncated at $-\$ 10,000$. State space $X$ is graphed on the right axis; control space $U$ is graphed on the left axis. The height of the surface reflects the present value of having base acreage $x_{t}$, planting $u_{t}$, and then subsequently following an optimal program. An optimal planting decision achieves the highest dollar value for each base acreage; thus, $\pi\left(x_{t}\right.$; $\theta$ ) is the projection of the surface's highest points onto the horizontal plane. The kink occurs when a farmer opts out of a program and the surface slopes down for $u_{t}>x_{t}$, because of the quadratic

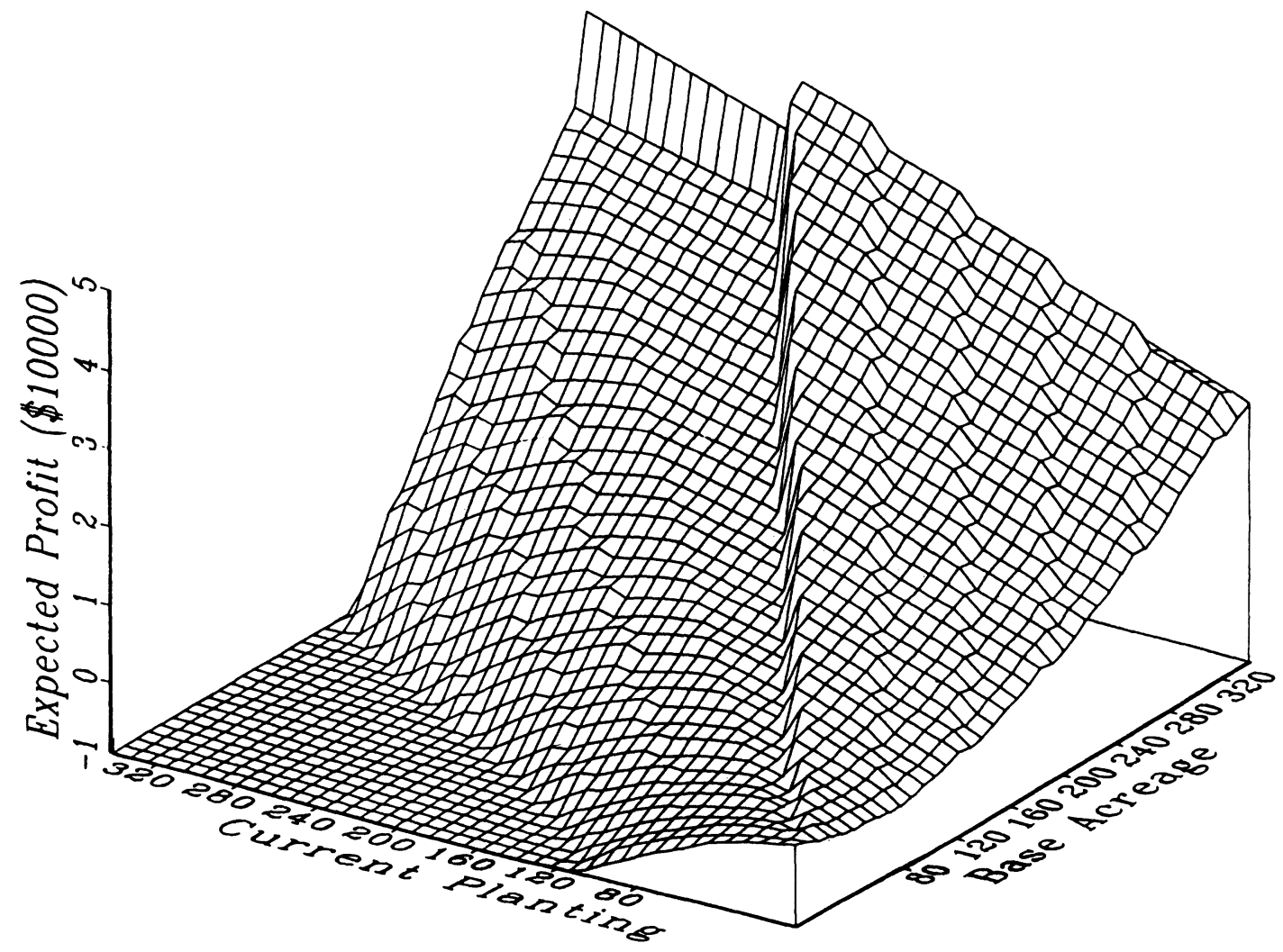

Figure 1. Low-yield corn farm, calibration 
penalty. The surface slopes up along the $X$ axis, because larger base entails higher profits.

Data in table 2 were used to calibrate the model's demand side. The demand elasticities allow for different domestic and foreign price responsiveness; they are derived from Roningen and Dixit. Domestic demand is typically less elastic than international demand. The difference between domestic production and total consumption established the value of the stock accumulation in (9).

Using a nested fixed-point algorithm, we simulated the solution to equation (10) to determine partial equilibrium for each crop. For each $p$, the inner part solved for the optimal policy $\pi\left(x_{t}\right.$; $\theta) .{ }^{8} \mathrm{We}$ actually solved two dynamic programs at each step: one for a low-yield farm and another for a high-yield farm. Then supply in (8) was calculated using the distributions of farm sizes and farm yields. The outer part of the algorithm checked the sign of excess demand. Then price was raised or lowered by $\$ .01$, and the inner algorithm was run again. Price $p$ is an

${ }^{8}$ Setting $\beta=1.05^{-1}$ for all simulations, we achieve convergence in the supremum norm on the order of $10^{-7}$, corresponding to $\$ .01$ for $\$ 100,000$ in present-value profits for the farmer. equilibrium if excess demand changes sign during the current iteration. ${ }^{9}$

\section{Empirical Findings}

Using the calibrated supplies, we solved first for equilibrium under the current American policy. Then we analyzed the five other policies described above. Tables 3, 4, and 5 abbreviate these six policies with subscripts. The status quo sets $\theta_{1}=(\tau, \gamma, \delta, \psi, L)$, where values of these parameters are given in table 1 . The second policy, which eliminates all subsidies, sets $\theta_{2}=(0$, $0,0,0,0)$ and constrains the transition function to be $\hat{z}\left(x_{t}, u_{t}\right)=x_{t}$. This shows what market conditions would be if subsidies were abolished and operators of large farms had permanently high fixed costs. The third policy, which freezes base acreage, corresponds to $\theta_{3}=\theta_{1}$ and transition rule $\hat{z}\left(x_{t}, u_{t}\right)=x_{t}$. Since fixed costs are part of

\footnotetext{
${ }^{9}$ The equilibrium may not be unique, and approximation to it can be wrong by as much as \$.02. Using the Gauss Programming Language, each simulation took approximately two minutes to converge on a personal computer with an 80286 chip and a math coprocessor.
}

Table 2. Data Used in Simulating the Demand Functions

\begin{tabular}{lcccrr} 
& \multicolumn{3}{c}{ (Billions of Units, Except for the Demand Elasticities) } \\
& $\begin{array}{c}\text { Domestic } \\
\text { Consumption }\end{array}$ & Exports & Production & $\varepsilon$ & $\varepsilon^{*}$ \\
\hline Corn & 6.041 & 1.716 & 8.877 & -0.21 & -1.176 \\
Cotton & 3.631 & 3.045 & 6.948 & -0.20 & -2.060 \\
Rice & 0.074 & 0.072 & 0.130 & -0.25 & -10.000 \\
Wheat & 1.086 & 1.598 & 2.108 & -0.35 & -2.696 \\
\hline
\end{tabular}

Sources: The data for domestic consumption, net exports, and domestic production are given in U.S. Department of Agriculture, Historical Commodity Data Series: 1950-1987. Each demand elasticity is calculated as an arc elasticity from the simulations reported in Roningen and Dixit.

Table 3. Is Farming Profitable Under These Policies?

\begin{tabular}{|c|c|c|c|c|c|c|}
\hline & $\theta_{1}$ & $\theta_{2}$ & $\theta_{3}$ & $\theta_{4}$ & $\theta_{5}$ & $\theta_{6}$ \\
\hline Corn, low & $\mathrm{Y}$ & $\mathbf{N}$ & $\mathrm{Y}$ & $\mathbf{N}$ & $\mathrm{Y}$ & $\mathbf{N}$ \\
\hline Corn, high & Y & $\mathrm{Y}$ & Y & $\mathrm{Y}$ & $\mathrm{Y}$ & $\mathrm{Y}$ \\
\hline Cotton, low & $\mathrm{N}$ & $\mathrm{N}$ & $\mathbf{N}$ & $\mathbf{N}$ & $\mathbf{N}$ & $\mathbf{N}$ \\
\hline Cotton, high & $\mathrm{Y}$ & $\mathrm{N}$ & $\mathrm{Y}$ & $\mathrm{Y}$ & $Y$ & $\mathrm{Y}$ \\
\hline Rice, low & $\mathrm{Y}$ & $\mathbf{N}$ & $\mathrm{Y}$ & $\mathbf{N}$ & $\mathrm{Y}$ & $\mathrm{N}$ \\
\hline Rice, high & $\mathrm{Y}$ & $\mathrm{N}$ & $\mathrm{Y}$ & $\mathrm{Y}$ & $\mathrm{Y}$ & $\mathrm{Y}$ \\
\hline Wheat, low & $\mathrm{Y}$ & $\mathbf{N}$ & $\mathrm{Y}$ & $\mathbf{N}$ & $Y$ & $\mathrm{~N}$ \\
\hline Wheat, high & $\mathrm{Y}$ & $\mathbf{N}$ & $\mathrm{Y}$ & $\mathrm{N}$ & $\mathrm{Y}$ & $\mathrm{N}$ \\
\hline
\end{tabular}

Note: $\theta_{1}$ is the simulated base case, $\theta_{2}$ abolishes the subsidies, $\theta_{3}$ freezes base acreage, $\theta_{4}$ halves Producer Subsidy Equivalent, $\theta_{5}$ increases diversion payments, and $\theta_{6}$ doubles the diversion requirement. 
Table 4. The Effects of the Six Different Policies

\begin{tabular}{|c|c|c|c|c|}
\hline & $\begin{array}{c}\text { Price } \\
\text { (dollars) }\end{array}$ & $\begin{array}{c}\text { Supply } \\
\text { (billions of units) }\end{array}$ & $\begin{array}{c}\text { Exports } \\
\text { (billions of units) }\end{array}$ & $\begin{array}{c}\text { Subsidies } \\
\text { (billions of dollars) }\end{array}$ \\
\hline Corn, 1987 data & 1.94 & 8.9 & 1.7 & 7.4 \\
\hline Corn, $\theta_{1}$ & 1.92 & 8.7 & 1.5 & 5.4 \\
\hline Corn, $\theta_{2}$ & 2.00 & 8.9 & 1.8 & 0.0 \\
\hline Corn, $\theta_{3}$ & 2.36 & 8.5 & 1.6 & 2.4 \\
\hline Corn, $\theta_{4}$ & 2.00 & 10.1 & 3.0 & 1.5 \\
\hline Corn, $\theta_{5}$ & 1.84 & 7.1 & -0.1 & 6.9 \\
\hline Corn, $\theta_{6}$ & 2.00 & 9.1 & 1.9 & 2.6 \\
\hline Cotton, 1987 data & 0.64 & 6.9 & 3.0 & 1.0 \\
\hline Cotton, $\theta_{1}$ & 0.62 & 7.0 & 3.1 & 0.4 \\
\hline Cotton, $\theta_{2}$ & 0.52 & 8.7 & 4.6 & 0.0 \\
\hline Cotton, $\theta_{3}$ & 0.58 & 7.4 & 3.5 & 0.4 \\
\hline Cotton, $\theta_{4}$ & 0.62 & 7.0 & 3.0 & 0.2 \\
\hline Cotton, $\theta_{5}$ & 0.62 & 7.0 & 3.1 & 0.6 \\
\hline Cotton, $\theta_{6}$ & 0.66 & 7.0 & 3.1 & 0.1 \\
\hline Rice, 1987 data & 7.27 & 0.13 & 0.07 & 0.5 \\
\hline Rice, $\theta_{1}$ & 7.23 & 0.13 & 0.08 & 0.2 \\
\hline Rice, $\theta_{2}$ & 6.83 & 0.19 & 0.13 & 0.0 \\
\hline Rice, $\theta_{3}$ & 7.25 & 0.13 & 0.07 & 0.2 \\
\hline Rice, $\theta_{4}$ & 7.13 & 0.14 & 0.09 & 0.1 \\
\hline Rice, $\theta_{5}$ & 7.31 & 0.13 & 0.07 & 0.3 \\
\hline Rice, $\theta_{6}$ & 7.25 & 0.13 & 0.07 & 0.1 \\
\hline Wheat, 1987 data & 2.57 & 2.1 & 1.6 & 3.3 \\
\hline Wheat, $\theta_{1}$ & 2.55 & 1.9 & 1.4 & 2.3 \\
\hline Wheat, $\theta_{2}$ & 2.25 & 2.8 & 2.3 & 0.0 \\
\hline Wheat, $\theta_{3}$ & 2.63 & 2.4 & 1.9 & 1.2 \\
\hline Wheat, $\theta_{4}$ & 2.83 & 2.1 & 1.7 & 0.5 \\
\hline Wheat, $\theta_{5}$ & 2.21 & 2.4 & 1.9 & 3.8 \\
\hline Wheat, $\theta_{6}$ & 2.85 & 2.0 & 1.6 & 0.6 \\
\hline
\end{tabular}

Note: The 1987 data are from the USDA's Historical Commodity Data Series: 1950-1987, and the other policies are as in table 3.

Table 5. The Supply Shares of Large Farms

\begin{tabular}{lcccccc} 
& $\theta_{1}$ & $\theta_{2}$ & $\theta_{3}$ & $\theta_{4}$ & $\theta_{5}$ & $\theta_{6}$ \\
\hline Corn & 17 & 29 & 24 & 21 & 20 & 20 \\
Cotton & 52 & 54 & 63 & 52 & 52 & 48 \\
Rice & 72 & 69 & 74 & 67 & 73 & 65 \\
Wheat & 36 & 56 & 65 & 53 & 28 & 54 \\
\hline
\end{tabular}

Note: A large farm is one with at least two hundred base acres, and all numbers are percentages. $\theta_{1}$ is the simulated base case, $\theta_{2}$ abolishes the subsidies, $\theta_{3}$ freezes base acreage, $\theta_{4}$ halves Producer Subsidy Equivalent, $\theta_{5}$ increases diversion payments, and $\theta_{6}$ doubles the diversion requirement.

cost function (2), this imposes a permanent penalty on large farms not covering average costs. The fourth policy, which halves PSE, is $\theta_{4}=$ $\left(\tau^{\prime}, \gamma / 2, \delta, \psi, L\right)$, where $\tau^{\prime}=(\tau+p) / 2$ and $p$ is price from the simulated base case. The fifth policy is given by $\theta_{5}=\left(\tau, \gamma^{\prime}, \delta, \psi, L\right)$, where $\gamma^{\prime}=\gamma+(\tau-p) / 2$ and $p$ is again the price from the simulated base case. This scenario in- creases diversion payments by half the $a d v a-$ lorem subsidy to farmers. The sixth case sets $\theta_{6}$ $=(\tau, \gamma, 2 \delta, \psi, L)$, doubling the proportion of land that farmers must leave fallow to qualify for subsidies.

To understand these policies fully, it would be necessary to graph all forty-eight value functions. Table 3 provides instead a summary of the policies' effects. Since (2) was calibrated using the full economic cost of planting, value functions are farmers' pure economic rent. Hence these functions are the incremental value accruing to a landowner who has maintained base acreage by following an optimal planting program. For example, using the functions for corn, we calculated that the purchase of a low-yield corn farm with 340 acres base includes a premium of about $\$ 145$ per acre above the price of such land without base. A high-yield corn farm commands an analogous premium of $\$ 405$ per acre. Table 3 indicates, for each policy and each farm type, whether these premiums are positive. 
A " $Y$ " indicates a profitable program; an " $\mathrm{N}$ " shows an unprofitable one.

We draw two conclusions from table 3 . First, farming in America would be unprofitable without subsidies. This finding corroborates the general conclusions about (negative) residual returns to management and risk, net of government payments, reported in McElroy, Ali, Dismukes, and Clauson. Second, most policies reducing subsidies make low-yield farms unprofitable. Lowering Producer Subsidy Equivalent makes the premiums on low-yield land negative for each of the four crops.

Figure 2 shows the value surface for a lowyield corn farm when subsidies are abolished. Contrasting this figure with figure 1 shows how government policy changes the nature of the optimal planting program. Units on the vertical axis are now hundreds of thousands of dollars of expected present-value losses, and the surface is truncated at $-\$ 100,000$. The axes are the same as in figure 1 , but now the surface slopes down along the $X$ axis because large low-yield corn farms are not remunerative. Farms with more than 160 acres of base are quite unprofitable because of their high sunk costs. The optimal planting program is simply to plant to capacity, minimizing expected losses.

Table 4 presents the entire array of simulation results. It concentrates on price, domestic supply, exports, and total subsidies. These policy simulations are valid, of course, only for the observed distributions of base acreage and postulated distribution of farm yields in 1987; since these distributions change only slowly, the simulations are germane for the first half of this decade. ${ }^{10}$ These summary effects do not take account of subsidy program participation rates, nor do they show the differential effects policies have on low-yield and high-yield farms or on small and large farms. We discuss these effects below.

Calibrations of the partial equilibria are all very good. For all four crops, the model matches the historical data for price, domestic supply, and exports. Because the model predicts low partic-

\footnotetext{
${ }^{10}$ There has been an upward trend in yields for these crops. Since program yields have been fixed for several years, farmers adopting efficient technologies will find participation less remunerative as time goes by. Therefore, our predictions about output and exports may be slightly conservative.
}

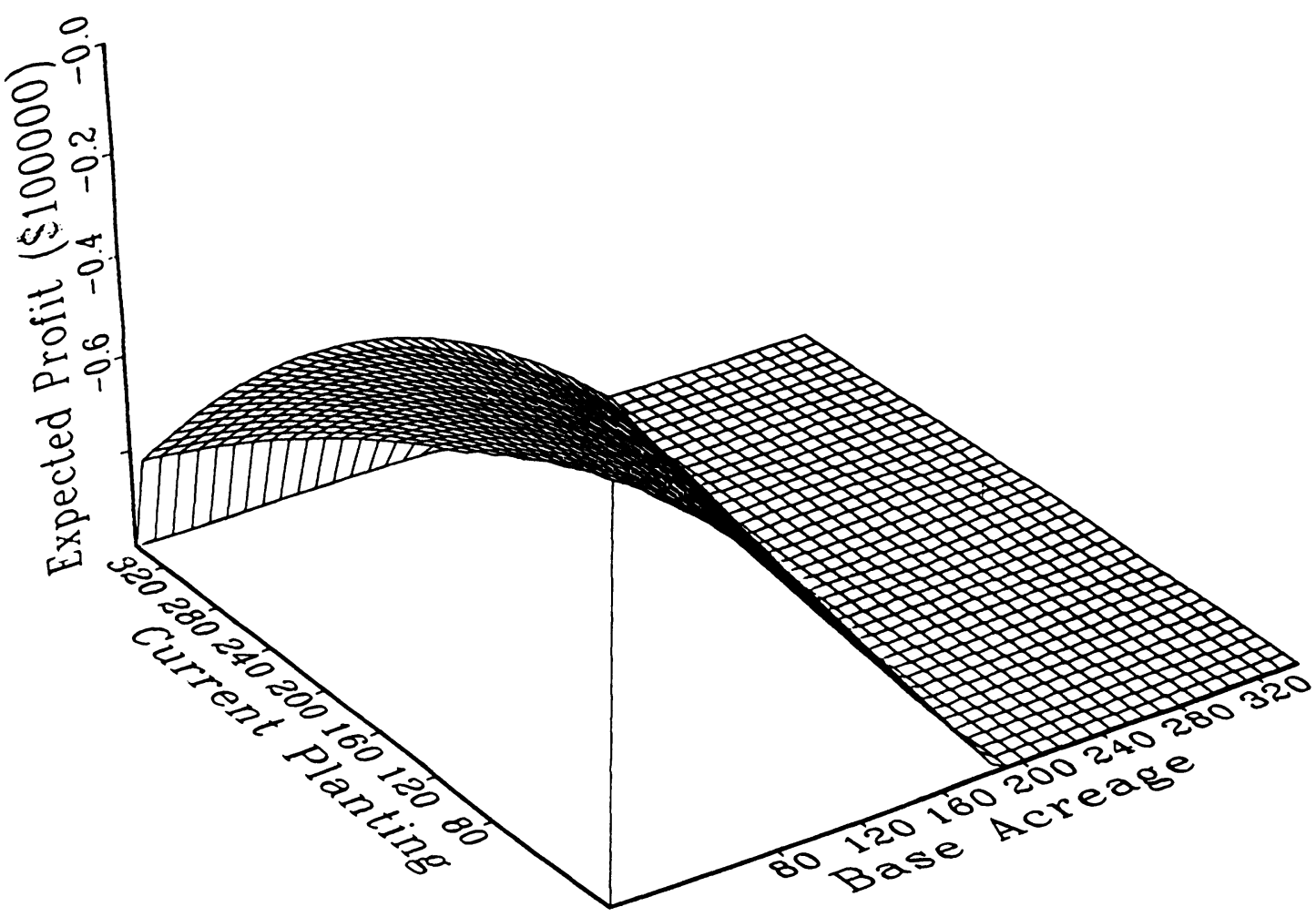

Figure 2. Low-yield corn farm, no subsidies 
ipation rates, it does not match subsidies very well, consistently predicting lower deficiency payments than actually occurred. Predicted participation rates for the calibrated equilibria were $56 \%$ for corn, $78 \%$ for cotton, $75 \%$ for rice, and $97 \%$ for wheat. The historical rates in 1987 were $91 \%$ for corn, $93 \%$ for cotton, $96 \%$ for rice, and $88 \%$ for wheat. When the model predicts a decision not to participate, it is almost always that of a high-yield farmer opting out.

Three general conclusions can be drawn from table 4. First, subsidy programs restrict output and raise the profitability of farming. ${ }^{11}$ This is clearly true for cotton, rice, and wheat, as is shown by comparing the predictions under $\theta_{2}$ with those under $\theta_{1}$. Second, policies designed to restrict farm output, such as increased diversion payments and increased diversion requirements, do not restrict production in the short run. Third, none of the policies has a radical effect on prices. This follows from the specification of costs of planting and high price elasticity of demand for American exports.

Freezing base acreage $\left(\theta_{3}\right)$ tends to raise prices and has equivocal effects on participation decisions. Since it is no longer possible to build up base, it is not worthwhile to opt out of the program for a year or two. Hence participation rates increase. But the lower aggregate output raises the world price of the crop. There is an off-setting tendency for large fertile farms to opt out of programs because the implicit subsidies inherent in deficiency payments are no longer as attractive.

Reducing producer subsidy equivalent $\left(\theta_{4}\right)$ has mixed effects. This policy has little impact on markets for cotton or rice, but it does change production decisions of corn and wheat farmers, lowering participation rates. This effect occurs for three reasons. First, subsidies are no longer as attractive to farmers with high yields, and some large farms divert fewer acres. Second, since these two crops have low penalties for expanding base acreage, several categories of corn farms with intermediate base acreage now find it worthwhile to build up base. Third, the programs are no longer profitable for wheat farmers, and large high-yield wheat farms minimize losses by opting out of the program. Of course, this policy uniformly reduces subsidies the American taxpayer must finance.

\footnotetext{
"This result follows from the specification of cost function (2) In de Gorter and Fisher, we reached a different conclusion using a cost function that did not penalize farmers for expanding base acreage.
}

Our results indicate that the GATT's emphasis on supply controls may be misguided for the United States. The two policies designed to explore this were $\theta_{5}$, increasing diversion payments, and $\theta_{6}$, doubling the diversion requirement. Consider the effects of $\theta_{5}$. Cotton, rice, and wheat farmers, who received no diversion payments in 1987, now find these programs more remunerative. Farmers with large base acreages might continue to participate, but farmers with small base and good land will tend to opt out in order to build up base. The net effect is not necessarily to decrease output.

Now consider $\theta_{6}$. Increasing the amount of land a farmer must leave fallow makes these programs less remunerative for high-yield farms with high base acreage. They may opt out of the programs. Indeed, participation rates for all four crops fall in the simulations of this policy scenario. In practice, neither of these policies seems to decrease exports or domestic production significantly.

The largest category of corn, cotton, rice, and wheat farms average $342,402,463$, and 440 base acres respectively. Table 5 shows how the different policies affect these farms. Abolishing subsidies increases the shares of large corn farms since farmers plant up to capacity, taking advantage of sunk costs. Programs reducing the profitability of wheat farming $\left(\theta_{2}, \theta_{3}, \theta_{4}\right.$, and $\left.\theta_{6}\right)$ have analogous effects. Finally, for all crops and policies, farms in the largest and penultimate categories undertake similar planting decisions, indicating that a finer sample of large farms would not change our results.

\section{Conclusion}

This paper applies dynamic programming to the political economy of American agricultural subsidies. Our model emphasizes that a farmer's expectations about farm yield and government policy influence the decision to seek subsidies. The model was calibrated using an adjustment cost penalizing farms for expanding plantings. We explored alternative policies, some of which may be outcomes of the Uruguay Round of the GATT.

The main policy conclusion is that abolishing the programs will increase exports and lower world prices of these crops. However, if we had used a cost function allowing farms to expand base easily, we would have found quite different results. A second important conclusion is that tightening supply controls may not decrease out- 
put. Indeed, a policy's effect depends upon current distributions of base acreage and land fertilities. If farmers perceive a policy reform is permanent, there may be an increase in current output in order to increase future subsidies. That some farms do build up base in anticipation of higher subsidies in an important consequence of these programs.

\section{References}

de Gorter, H. and E. O'N. Fisher. "The Dynamic Effects of Agricultural Subsidies in the United States." Unpublished manuscript, Cornell University (1991).

Gardner, B. L. "Recent Studies of Agricultural Trade Liberalization." Pages 361-379 in A. Maunder and A. Valdés, editors, Agriculture and Governments in an Independent World. Brookfield, Vermont: Gower Publishing Company Paper, 1990.

General Agreement on Tariffs and Trade. Mid-Term Meeting, MTN.TNC/11. Geneva, April 1989a.

General Agreement on Tariffs and Trade. "The EC Approach on Aggregate Measures of Support." MTN.GNG/NGS/W/96. Geneva, July 1989b.

Hertel, T. W. "Negotiating Reductions in Agricultural Support: Implications of Technology and Factor Mobility." Amer. J. of Agr. Econ. 71 (1989), 559-573.

International Agricultural Trade Research Consortium. "Potential Use of an Aggregrate Measure of Support." Commission Paper Number 5 (1990a).

International Agricultural Trade Research Consortium. "The Comprehensive Proposals for Negotiations in Agriculture." Commission Paper Number 7 (1990b).
McCalla, A. F. and T. E Josling. Agricultural Policies and World Markets. New York: Macmillan Publishing Co., 1985.

McElroy, R., M. Ali, R. Dismukes, and A. Clauson. Costs of Production for Major U.S. Crops. United States Department of Agriculture, Economic Research Service, Agriculture and Rural Economy Division, Staff Report Number AGES 89-22, 1989.

Robinson, S. “Analyzing Agricultural Trade Liberalization with Single Country Computable General Equilibrium Models" in I. Goldin and O. Knudsen, editors, Agricultural Trade Liberalization: Implications for Developing Countries. Paris: Organization for Economic Cooperation and Development, 1990.

Roningen, V. and P. Dixit. "Economic Implications of Agricultural Policy Reforms in Industrial Market Economies." United States Department of Agriculture, Economic Research Service, Agricultural Trade Analysis Division, Staff Report Number AGES 89-36, 1989.

Rust, J. "Optimal Replacement of GMC Bus Engines: An Empirical Model of Harold Zurcher." Econometrica 55 (1987), 999-1033.

Schmitz, A., D. Sigurdson, and O. Doering. "Domestic Farm Policy and the Gains from Trade." Am. J. Agr. Econ. 68 (1986), 820-827.

Trela, I., J. Whalley, and R. Wigle "International Trade in Grain: Domestic Policies and Trade Conflicts.” Scand. J. Econ. 89 (1987), 271-283.

Tyers, R. and K. Anderson. "Liberalizing OECD Agricultural Policies in the Uruguay Round: Effects on Trade and Welfare." J. of Agr. Econ. 30 (1988), 197-215.

United States. Public Law 99-198. Food Security Act of 1985. December 23, 1985.

United States Department of Agriculture, Agricultural Stabilization and Conservation Service, Commodity Analysis Division. Historical Commodity Data Series: 1950 1987, July 1990.

Wallace, T. D. "Measures of Social Costs of Agricultural Programs.” J. Farm Econ. 44 (1962), 580-594. 